\title{
Hybrid Solutions for the Surgical Treatment of Multilevel Degenerative Cervical Disk Disease
}

\author{
Stefan Alexander König ${ }^{1} \quad$ Sebastian Ranguis ${ }^{2} \quad$ Uwe Spetzger $^{1}$ \\ 1 Neurochirurgische Klinik, Klinikum Karlsruhe, Karlsruhe, Germany \\ 2 Department of Neurosurgery, Prince of Wales Hospital, Randwick, \\ New South Wales, Australia \\ Address for correspondence Stefan Alexander König, MD, \\ Neurochirurgische Klinik, Klinikum Karlsruhe, Moltkestr. 90, D-76133 \\ Karlsruhe, Germany (e-mail: koenig_de@web.de).
}

Surg J 2015;1:e16-e22.

\begin{abstract}
Background In different stages of cervical degenerative disk disease, the combination of dynamic and nondynamic implants may be considered. The aim of this study was to investigate the applicability of criteria to assist decision making in these cases.

Methods Thirty patients with spondylotic cervical radiculopathy and a coincidence of soft disk and hard disk herniation were surgically treated with a hybrid solution (combination of total disk replacement and cage fusion). The control group included 32 patients who underwent two-level cage fusion. Pre- and postoperative Japanese Orthopaedic Association (JOA) scores and range of motion (ROM) were compared.

Results Twenty-three patients underwent two-level hybrid solution and 7 underwent three-level treatment. The most frequent solution $(n=13)$ was a combination of a dynamic implant at $\mathrm{C} 5-\mathrm{C} 6$ and a nondynamic implant at C6-C7. The mean JOA score improved from 13.9 to 15.6 points after surgery (mean deviation [MD] 1.6, 95\% confidence interval $[\mathrm{Cl}] 2.1$ to $1.2, p<0.001$ ). ROM showed a slight trend to increase (MD $0.8,95 \% \mathrm{Cl}-0.9$ to 2.6, $p=0.193$ ). In the control group, the mean JOA score

Keywords

- cervical spine

- degeneration

- fusion

- disk replacement

- hybrid surgery improved from 13.3 to 15.1 points after surgery (MD 1.4, 95\% $\mathrm{Cl} 2.1$ to 1.2, $p<0.001$ ). The comparison of the postoperative JOA scores and recovery rates between the hybrid treatment group and the control group did not show significant differences.

Conclusions In cases of coincident soft and hard degenerative cervical disk disease at adjacent levels, the combination of a disk prosthesis and a nondynamic implant is a safe and effective treatment option and an alternative to multilevel fusion.
\end{abstract}

The mean age of patients with treatment-relevant degenerative disease of the cervical spine is $\sim 50$ years, and at this age, preserving motion in an operated level is desirable. ${ }^{1-9}$ Nevertheless, some patients have bony degeneration with reduced motion, osteochondrosis, and a loss in disk height, and in this group, a disk prosthesis is not indicated. Thus, in cases with two- or three-level disk disease with different stages of degeneration, the combination of dynamic and nondynamic implants may be considered. ${ }^{10-15}$

received

June 15, 2015

accepted after revision

September 24, 2015

published online

November 19, 2015
The aim of this study was to investigate the applicability of criteria to assist decision making in these cases. The preand postoperative outcomes measured were radiologic evidence of range of motion (ROM) and clinical symptoms reported according to the Japanese Orthopaedic Association (JOA) scores as well as recovery rates. Furthermore, the authors report on their experiences with the implantation of disk prostheses combined with one or two cages in adjacent levels. Tel: +1(212) 584-4662.
$($ (1) $\circledast$
Copyright $@ 2015$ by Thieme Medical Publishers, Inc., 333 Seventh Avenue, New York, NY 10001, USA.

License terms $10.1055 / \mathrm{s}-0035-1567876$ ISSN 2378-5128. 


\section{Patients and Methods}

Between January 2009 and August 2011, our department treated 30 patients ( 15 women, 15 men) for degenerative cervical disk disease using a hybrid operative solution (dynamic plus nondynamic implant[s]). The average age was 50.7 years (range 38 to 71). All patients were diagnosed preoperatively with a radiculopathy and/or myelopathy. Pre- and postoperative JOA scores were compared with an average follow-up time of 1.5 years (range 0.5 to 3.0 ).
Furthermore, a control group with 32 patients (16 men, 16 women) who underwent two-level cage fusion was analyzed. The mean age of the patients from that group was 61.9 years (range 40 to 78 years).

The following criteria were considered for total disk replacement with a dynamic implant: biological age of the patient $<55$ years (with four exceptions due to a good condition of the disk); and/or soft disk herniation without significant osteochondrosis; and/or ROM $>5$ degrees in the sagittal plane in preoperative radiographic images.

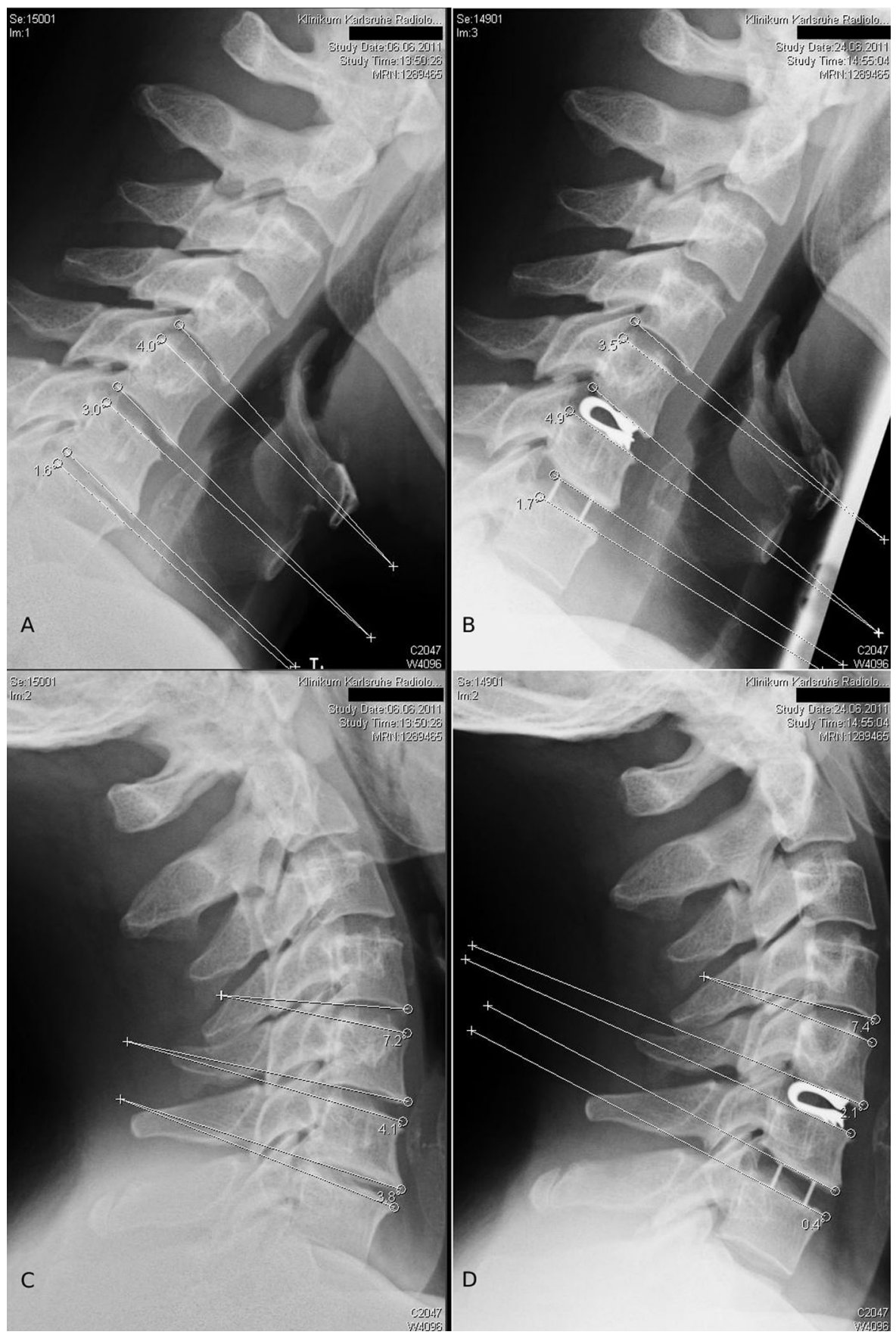

Fig. 1 Hybrid construct with a combination of a dynamic implant (DCl dynamic cervical implant [Paradigm Spine, Wurmlingen, Germany]) and an adjacent nondynamic implant (Shell Cage [Advanced Medical Technologies, Nonnweiler, Germany]). Lateral X-ray images in flexion position before (A) and after (B) surgery. Lateral X-ray images in extension position before (C) and after (D) surgery. 
Treatment with a nondynamic implant was taken into account in the presence of the following criteria: hard disk degeneration with significant loss of height of the intervertebral disk space $(<4 \mathrm{~mm})$ and/or ROM $<5$ degrees in the sagittal plane in preoperative radiographic images.

The following implants were used for dynamic total disk replacement at the cervical spine: DCI dynamic cervical implant (Paradigm Spine, Wurmlingen, Germany); Mobi-C cervical disk prosthesis (LDR Médical, Troyes, France); and M6C artificial disk (Spinal Kinetics, California, United States).
The dynamic implants were combined with two different nondynamic techniques: implantation of a Shell Cage (Advanced Medical Technologies, Nonnweiler, Germany) or interposition of polymethyl methacrylate (Palacos or Osteopal by Heraeus Medical, Wehrheim, Germany).

One hundred twenty pre- and postoperative functional $\mathrm{X}$-ray images in flexion and extension of the 30 patients (four images per patient) from the hybrid treatment group were analyzed. A modification of White and Panjabi's

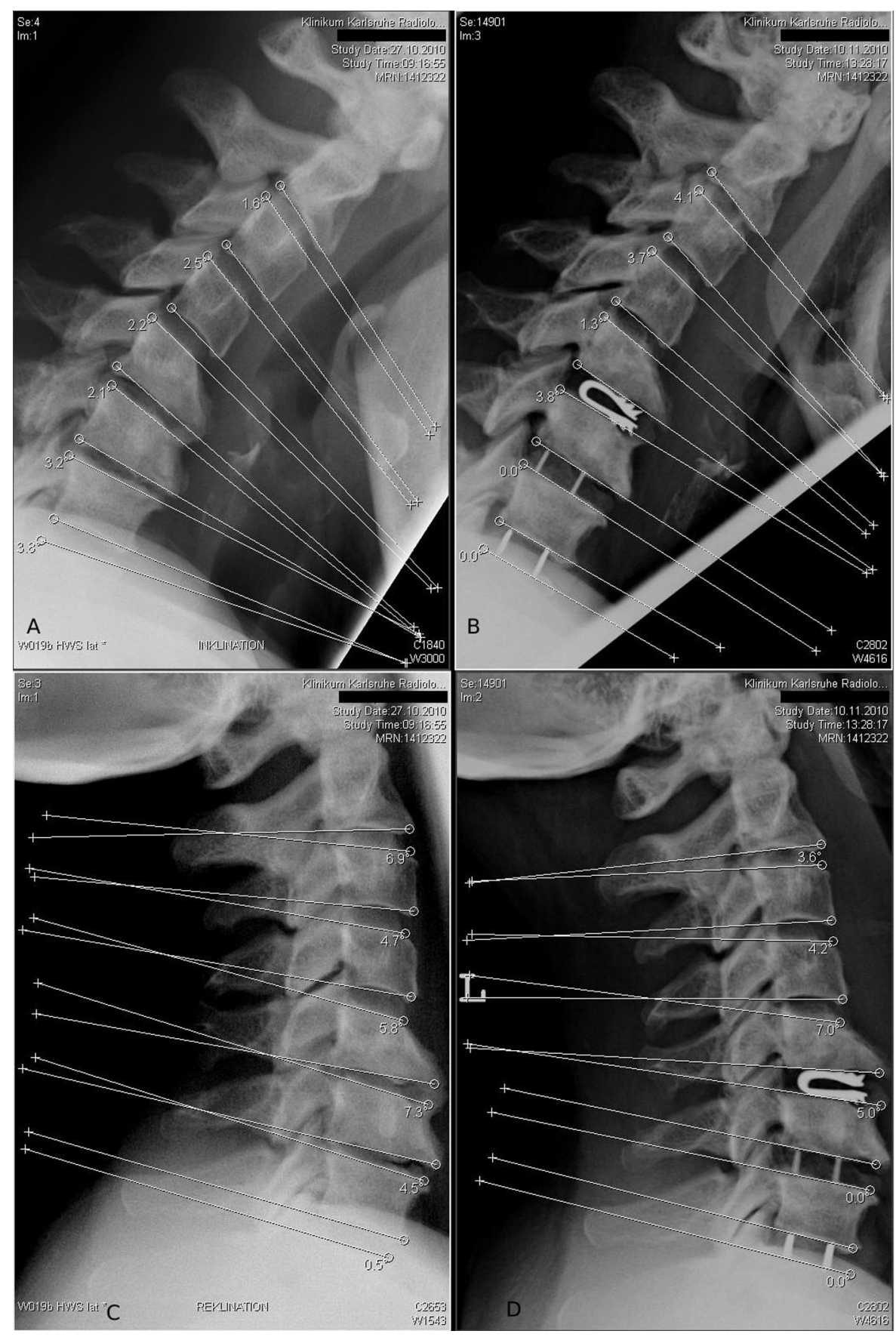

Fig. 2 Three-level hybrid solution with a combination of a dynamic implant (DCI dynamic cervical implant [Paradigm Spine, Wurmlingen, Germany]) and two nondynamic implants (Shell Cage [Advanced Medical Technologies, Nonnweiler, Germany]) in adjacent levels. Lateral X-ray images in flexion position before (A) and after (B) surgery. Lateral X-ray images in extension position before (C) and after (D) surgery. 
method was used with the Cobb angle measurement tool (Centricity Enterprise Web V3.0 software, GE Healthcare, Little Chalfont, United Kingdom) to measure the ROM angles. ${ }^{16-18}$ Angle values in kyphosis, as usually observed in flexion (-Fig. 1A, C), were recorded as positive values, and angle values in lordosis, as usually observed in extension, were recorded as negative values (-Fig. 1B, D). The difference of both values results in the total range of motion (ROM) in the sagittal plane. For example, ROM of the treated level C5-C6 in - Fig. 2 (B, D) is 3.8 degrees - ( -5.0 degrees $)$ $=8.8$ degrees.
The pre- and postoperative radiologic and clinical data were analyzed retrospectively. The Student $t$ test was used to compare paired outcomes for the hybrid treatment group as well as for the two-level fusion group. Furthermore, the authors compared the postoperative JOA scores and the recovery rate of both group.

\section{Results}

\section{Hybrid Treatment Group}

Twenty-three patients were treated with a two-level hybrid solution and seven patients underwent three-level treatment

Table 1 Type of implants and cervical levels being treated

\begin{tabular}{|c|c|c|c|c|c|}
\hline & & & Implant & & \\
\hline Patient no. & Age (y) & Sex & First level & Second level & Third level \\
\hline 1 & 49 & $\mathrm{~F}$ & $\mathrm{DCl}$ C5-C6 & PMMA C6-C7 & - \\
\hline 2 & 71 & $\mathrm{~F}$ & DCl C5-C6 & SC C6-C7 & - \\
\hline 3 & 38 & $\mathrm{M}$ & $\mathrm{DCl}$ C5-C6 & PMMA C6-C7 & - \\
\hline 4 & 55 & $\mathrm{~F}$ & DCl C5-C6 & SC C6-C7 & - \\
\hline 5 & 42 & $\mathrm{M}$ & $\mathrm{DCl}$ C6-C7 & SC C7-T1 & - \\
\hline 6 & 56 & $\mathrm{M}$ & $\mathrm{DCl}$ C5-C6 & PMMA C6-C7 & - \\
\hline 7 & 53 & $\mathrm{~F}$ & $\mathrm{DCl}$ C5-C6 & PMMA C6-C7 & - \\
\hline 8 & 49 & $\mathrm{M}$ & DCl C5-C6 & PMMA C6-C7 & - \\
\hline 9 & 53 & $\mathrm{~F}$ & $\mathrm{DCl} C 5-\mathrm{C} 6$ & PMMA C6-C7 & - \\
\hline 10 & 43 & $\mathrm{M}$ & M6 C5-C6 & SC C6-C7 & - \\
\hline 11 & 51 & $\mathrm{M}$ & SC C5-C6 & $\mathrm{DCl} 6-\mathrm{C} 7$ & - \\
\hline 12 & 61 & $\mathrm{~F}$ & $\mathrm{DCl}$ C6-C7 & PMMA C7-T1 & - \\
\hline 13 & 42 & $\mathrm{~F}$ & $\mathrm{MoC}$ C5-C6 & SC C6-C7 & - \\
\hline 14 & 47 & $\mathrm{M}$ & $\mathrm{DCl} C 4-\mathrm{C} 5$ & SC C5-C6 & - \\
\hline 15 & 50 & $\mathrm{~F}$ & $\mathrm{DCl}$ C5-C6 & SC C6-C7 & - \\
\hline 16 & 55 & $\mathrm{M}$ & $\mathrm{DCl}$ C4-C5 & PMMA C5-C6 & - \\
\hline 17 & 45 & $\mathrm{~F}$ & $\mathrm{DCl} C 4-\mathrm{C} 5$ & SC C5-C6 & - \\
\hline 18 & 37 & $\mathrm{M}$ & DCl C5-C6 & SC C6-C7 & - \\
\hline 19 & 46 & $\mathrm{~F}$ & $\mathrm{MoC}$ C5-C6 & SC C6-C7 & - \\
\hline 20 & 41 & $\mathrm{M}$ & PMMA C4-C5 & $\mathrm{DCl}$ C5-C6 & - \\
\hline 21 & 43 & $M$ & SC C5-C6 & $\mathrm{DCl}$ C6-C7 & - \\
\hline 22 & 55 & $\mathrm{~F}$ & $\mathrm{DCl}$ C5-C6 & PMMA C6-C7 & - \\
\hline 23 & 66 & $\mathrm{M}$ & $\mathrm{DCl} C 4-\mathrm{C} 5$ & SC C5-C6 & - \\
\hline 24 & 55 & $\mathrm{~F}$ & MoC C4-C5 & PMMA C5-C6 & PMMA C6-C7 \\
\hline 25 & 49 & $\mathrm{M}$ & $\mathrm{DCl} C 3-\mathrm{C} 4$ & PMMA C4-C5 & PMMA C5-C6 \\
\hline 26 & 44 & $\mathrm{M}$ & $\mathrm{DCl} C 4-\mathrm{C} 5$ & SC C5-C6 & $\mathrm{DCl}$ C6-C7 \\
\hline 27 & 68 & $\mathrm{M}$ & PMMA C4-C5 & $\mathrm{DCl}$ C5-C6 & $\mathrm{DCl}$ C6-C7 \\
\hline 28 & 54 & $\mathrm{~F}$ & $\mathrm{DCl}$ C4-C5 & SC C5-C6 & SC C6-C7 \\
\hline 29 & 45 & $\mathrm{~F}$ & $\mathrm{DCl} C 4-\mathrm{C} 5$ & DCl C5-C6 & SC C6-C7 \\
\hline 30 & 44 & $f$ & $\mathrm{DCl}$ C5-C6 & SC C6-C7 & SC C7-T1 \\
\hline
\end{tabular}

Abbreviations: DCI, DCI dynamic cervical implant (Paradigm Spine, Wurmlingen, Germany); M6, M6C artificial disk (Spinal Kinetics, California, United States); MoC, Mobi-C cervical disk prosthesis (LDR Médical, Troyes, France); PMMA, polymethyl methacrylate (Palacos or Osteopal by Heraeus Medical, Wehrheim, Germany); SC, Shell Cage (Advanced Medical Technologies, Nonnweiler, Germany). 
(-Table 1). Of dynamic implants used, 29 were the DCI dynamic cervical implant, 3 were the Mobi-C cervical disk prosthesis, and 1 was the M6C artificial disk. Nineteen levels were treated with nondynamic Shell-Cage, and 15 with Palacos or Osteopal.

The most frequent solution $(n=13)$ was a combination of a dynamic implant at $\mathrm{C} 5-\mathrm{C} 6$ and a nondynamic implant at C6-C7. This was to achieve a more natural ROM at C5-C6 (-Table 1, -Figs. 1 and 3). These levels were most frequently affected by degeneration. Only one patient was operated at C3-C4 (DCI). Ten patients required an implant at C4-C5 with 7 of these being dynamic implants. The 3 patients operated at the C7-T1 level received a fusion implant (-Table 1).

No patient required revision surgery for primary or secondary implant dislocation. We did not observe secondary instability following the multilevel treatment. There were no revision surgeries for other postoperative complications.

The mean JOA score improved from 13.9 to 15.6 points after surgery (mean deviation [MD] 1.6, 95\% confidence interval $[\mathrm{CI}] 2.1$ to $1.2, p<0.001)$. ROM at the level treated

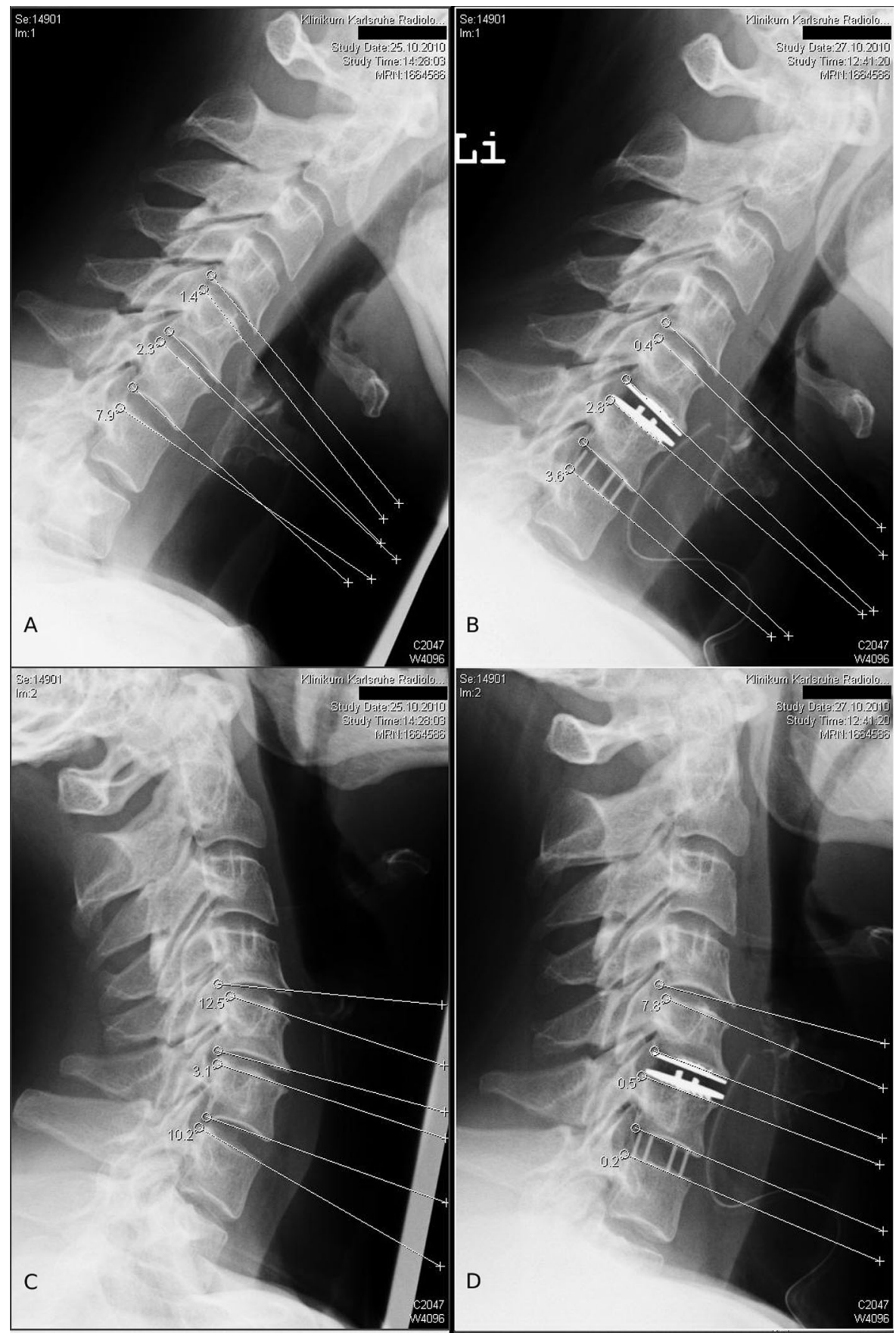

Fig. 3 Hybrid construct with a combination of a dynamic implant (Mobi-C cervical disk prosthesis [LDR Médical, Troyes, France]) and an adjacent nondynamic implant (Shell Cage [Advanced Medical Technologies, Nonnweiler, Germany]). Lateral X-ray images in flexion position before (A) and after (B) surgery. Lateral X-ray images in extension position before (C) and after (D) surgery. 
with a dynamic implant showed a slight trend to increase, from a mean of 6.0 degrees to 6.8 degrees (MD 0.8, 95\% CI -0.9 to $2.6, p=0.193$ ). It is likely that the study was underpowered to detect a significant change in ROM.

\section{Control Group}

Twenty-four patients were treated with a Shell-Cage, and 8 patients with Palacos or Osteopal; 22 of the 32 patients from the control group had a two-level fusion at the C5-C6 and the $\mathrm{C} 6-\mathrm{C} 7$ level. Ten patients underwent fusion at C4-C5 and C5-C6.

No patient required revision surgery for primary or secondary implant dislocation. We did not observe secondary instability following the multilevel treatment. There were no revision surgeries for other postoperative complications.

The mean JOA score improved from 13.3 to 15.1 points after surgery (MD 1.4, 95\% CI 2.1 to $1.2, p<0.001$ ). Postoperative JOA scores between the hybrid treatment group and the control group showed no significant difference. The recovery rates showed almost equal clinical outcomes of both groups: 1.09 for the hybrid treatment group, and 1.19 for the control group.

\section{Discussion}

Disk herniation and moderate osteochondrosis of cervical segments are phenomena usually encountered in the fifth decade of life. In cases of multilevel cervical disk disease at varying stages of degeneration, a differentiated treatment approach aiming to partially preserve motion may be of more benefit than anterior plating or even posterior fixation. ${ }^{2,4-9}$ For this reason, the authors consider certain criteria such as biological age of the patient, condition of the disk (soft/hard), height of the intervertebral space, appearance of osteophytes, and ROM in the sagittal plane, which may indicate a hybrid solution in selected cases. Other authors have reported good results in a small number of patients following hybrid solutions using other implants. ${ }^{12-14,19}$ Furthermore, positive results following multilevel total disk replacement in younger patients have also been reported.,20 Our results provide further evidence to support the use of hybrid constructs as an alternative to multilevel fusion in selected patients.

The measurement of ROM in the sagittal plane using lateral functional radiologic images is required to correctly identify patients amenable to hybrid treatment.

When ROM is more than 5 degrees in combination with a soft disk on magnetic resonance imaging, then treatment with a dynamic implant should be considered. ${ }^{15,21}$ If ROM in the sagittal plane is less than 5 degrees combined with a hard disk and osteophytes on magnetic resonance imaging, then treatment with a fusion implant is suggested. ${ }^{12,19,22-25}$ A coincidence of two varying conditions in adjacent cervical levels should lead to a consideration for a hybrid construct utilizing both dynamic and fusion implants (disk prosthesis plus cage), which is a safe and effective alternative to multilevel fusion.

\section{Conclusion}

In cases of coincident soft and hard degenerative cervical disk disease at adjacent levels, the combination of a disk prosthesis and a nondynamic implant is a safe and effective alternative to a multilevel fusion.

\section{References}

1 Barbagallo GM, Assietti R, Corbino L, et al. Early results and review of the literature of a novel hybrid surgical technique combining cervical arthrodesis and disc arthroplasty for treating multilevel degenerative disc disease: opposite or complementary techniques? Eur Spine J 2009;18(Suppl 1):29-39

2 Barrey C, Campana S, Persohn S, Perrin G, Skalli W. Cervical disc prosthesis versus arthrodesis using one-level, hybrid and twolevel constructs: an in vitro investigation. Eur Spine J 2012;21(3): 432-442

3 Cardoso MJ, Rosner MK. Multilevel cervical arthroplasty with artificial disc replacement. Neurosurg Focus 2010;28(5):E19

4 Cho BY, Lim J, Sim HB, Park J. Biomechanical analysis of the range of motion after placement of a two-level cervical ProDisc-C versus hybrid construct. Spine 2010;35(19):1769-1776

$5 \mathrm{Du}$ J, Li M, Liu H, Meng H, He Q, Luo Z. Early follow-up outcomes after treatment of degenerative disc disease with the discover cervical disc prosthesis. Spine J 2011;11(4):281-289

6 Gebremariam L, Koes BW, Peul WC, Huisstede BM. Evaluation of treatment effectiveness for the herniated cervical disc: a systematic review. Spine 2012;37(2):E109-E118

7 Korge A, Siepe CJ, Heider F, Mayer HM. [Total cervical disk replacement-implant-specific approaches: keel implant (Prodisc-C intervertebral disk prosthesis)]. Oper Orthop Traumatol 2010;22(5-6):480-494

8 Park SB, Jahng TA, Chung CK. Remodeling of adjacent spinal alignments following cervical arthroplasty and anterior discectomy and fusion. Eur Spine J 2012;21(2):322-327

9 Svedmark P, Lundh F, Németh G, et al. Motion analysis of total cervical disc replacements using computed tomography: preliminary experience with nine patients and a model. Acta Radiol 2011; 52(10):1128-1137

10 Goel VK, Faizan A, Palepu V, Bhattacharya S. Parameters that effect spine biomechanics following cervical disc replacement. Eur Spine J 2012;21(Suppl 5):S688-S699

11 Kepler CK, Hilibrand AS. Management of adjacent segment disease after cervical spinal fusion. Orthop Clin North Am 2012;43(1): 53-62, viii

12 Lee MJ, Dumonski M, Phillips FM, et al. Disc replacement adjacent to cervical fusion: a biomechanical comparison of hybrid construct versus two-level fusion. Spine 2011;36(23): 1932-1939

13 Shin DA, Yi S, Yoon DH, Kim KN, Shin HC. Artificial disc replacement combined with fusion versus two-level fusion in cervical two-level disc disease. Spine 2009;34(11):1153-1159, discussion 1160-1161

14 Terai T, Faizan A, Sairyo K, Goel VK. Operated and adjacent segment motions for fusion versus cervical arthroplasty: a pilot study. Clin Orthop Relat Res 2011;469(3):682-687

15 Kowalczyk I, Lazaro BC, Fink M, Rabin D, Duggal N. Analysis of in vivo kinematics of 3 different cervical devices: Bryan disc, ProDisc-C, and Prestige LP disc. J Neurosurg Spine 2011;15(6): 630-635

16 König A, Vitzthum HE. Functional MRI of the spine: different patterns of positions of the forward flexed lumbar spine in healthy subjects. Eur Spine J 2001;10(5):437-442 
17 Vitzthum HE, König A, Seifert V. Dynamic examination of the lumbar spine by using vertical, open magnetic resonance imaging. J Neurosurg 2000;93(1, Suppl):58-64

18 White AA, Panjabi MM. Clinical Biomechanics of the Spine. 2nd ed. Philadelphia, PA: JB Lippincott; 1990:58-62

19 Lee SH, Im YJ, Kim KT, Kim YH, Park WM, Kim K. Comparison of cervical spine biomechanics after fixed- and mobile-core artificial disc replacement: a finite element analysis. Spine 2011;36(9): 700-708

20 Cardoso MJ, Mendelsohn A, Rosner MK. Cervical hybrid arthroplasty with 2 unique fusion techniques. J Neurosurg Spine 2011; 15(1):48-54

21 Guérin P, Obeid I, Gille O, et al. Sagittal alignment after single cervical disc arthroplasty. J Spinal Disord Tech 2012;25(1):10-16
22 Richards O, Choi D, Timothy J. Cervical arthroplasty: the beginning, the middle, the end? Br J Neurosurg 2012;26(1):2-6

23 Finn MA, Samuelson MM, Bishop F, Bachus KN, Brodke DS. Twolevel noncontiguous versus three-level anterior cervical discectomy and fusion: a biomechanical comparison. Spine 2011;36(6): 448-453

24 Koller H, Hempfing A, Ferraris L, Maier O, Hitzl W, Metz-Stavenhagen P. 4- and 5-level anterior fusions of the cervical spine: review of literature and clinical results. Eur Spine J 2007;16(12): 2055-2071

25 Womack W, Leahy PD, Patel VV, Puttlitz CM. Finite element modeling of kinematic and load transmission alterations due to cervical intervertebral disc replacement. Spine 2011;36(17): E1126-E1133 